\title{
Occupational Fatigue: Impact on Anesthesiologist's Health and the Safety of Surgical Patients
}

\author{
As anesthesiologists we are frequently working in a stressful environment. \\ Do you disagree with this?
}

Anesthesiology is a medical specialty that has been singled out as having made major advances in patient care safety over the past few decades. Both morbidity and mortality rates have undergone significant improvements due to innovations in pharmacology, monitoring and clinical approaches. However, patient harm secondary to errors made by anesthesia practitioners continues to exist in spite of the many other advances. One key cause for practitioner error that is well documented in the medical literature is the practitioner's level of fatigue ${ }^{1,2}$.

Increasing work pressure demands coupled with personal and social commitments can be very heavy at times, frequently resulting in Fatigue Syndrome in clinical anesthesiologists. Interestingly, "fatigue" (also called exhaustion, tiredness, lethargy, languidness, languor, lassitude, and listlessness) can be differentiated into physical and mental categories.

Physical fatigue can be defined as the inability to continue functioning at the level of one's normal abilities, and usually becomes particularly noticeable during heavy exercise, though varying from a general state of lethargy to a specific work-induced burning sensation within one's muscles ${ }^{3}$. Though anesthesiologists may experience physical fatigue in the course of a busy workday, it is mental fatigue that serves as the primary causative agent for committing medical error among anesthesia practitioners. Mental fatigue manifests as somnolence (sleepiness) with the inability to concentrate or make rapid assessments and decisions. It is this mental state that is impacting anesthesiologists' performance and putting the safety of surgical patients at risk! For decades the job of an anesthesiologist has been described as hours of boredom, interspersed with moments of terror. The key issue is to determine approaches that can be taken to prevent hours of boredom from interfering with good medical judgment when moments of terror occur.

One study showed that the risk of an accident (medical err) increases exponentially with each hour after nine consecutive hours of work. At 24 hours of sustained wakefulness, the impairment in physicians' psychomotor function may be equivalent to a blood alcohol concentration of $0.1 \%$, which is at or above the legal limit for driving in most states in the USA ${ }^{4}$.

Christopher P. Landrigan highlights the importance of this subject, when he mentions in the American Joint Commission Sentinel Event Alert that "We, anesthesiologists, have a culture of working long hours and the impact of fatigue has not been a part of our consciousness". On the other hand, The Institute of Medicine's report "To Err Is Human: Building a Safer Health System," reveals that medical errors contribute to many hospital deaths and serious adverse events ${ }^{5,6}$.

Studying fatigue, whether in the laboratory or clinical setting, is highly complex and difficult due to the multifactorial nature of fatigue, the variance over time with different individuals and the overlap of other associated conditions such as Burnout Syndrome, Chemical Dependence, Suicidality and Stress. Nevertheless, the need to study fatigue and the best ways to control it in our medical practices is paramount. Physicians are trained to practice with a patient-centered focus. This often means we ignore our own health and well being. However, when the health of the medical practitioner directly impacts on patient well being, we must turn our attention toward ourselves. In regard to fatigue this means learning to recognize it and learning ways to mitigate its effects, lest this latent threat evolve into patient harm ${ }^{7}$.

In regard to fatigue and long work hours, there are a few countries that have taken this issue head on. The Association of Anaesthetists of Great Britain and Ireland produced a 25-page document specifically dealing with the problem of fatigue in their members and made recommendations to alleviate the personal and patient safety issues of this problem ${ }^{8}$. Similarly, the Australian and New Zealand College of Anaesthetists also produced a statement on fatigue where specific principles and responsibilities are defined for individual anesthesiologists, anesthesia departments and hospitals in order to reduce fatigue and attendant medical errors resulting from fatigue 9 .

In fact, specific recommendations in the United States concerning stringent limitations in work hours of medical residents in training came directly from the recognition that fatigue in the trainee was not only harmful to the trainee, 
but also had the potential for producing major adverse effects on patient safety ${ }^{10,11}$. Though resident in training work hours have been curtailed, the same cannot be said for the attending anesthesiologist ${ }^{12}$. The concern for the fatigued physician making errors is becoming recognized at national levels and in December 2011 the Joint Commission issued an alert outlining the concerns about fatigue in health care workers as well as approaches that should be taken to reduce this problem ${ }^{13}$.

The American Joint Commission - "Sentinel Event Alert" urges greater attention to preventing fatigue and its consequences (Burnout Syndrome, Chemical Dependence, Suicidality, etc.) among health care workers and they suggest specific actions for health care organizations in order to mitigate these risks ${ }^{13}$.

The purpose of "Sentinel Event Alert" is to address the effects and risks of an extended work day as well as the cumulative effect of many days of extended work hours. The Joint Commission Alert makes a number of recommendations for health care organizations, such as medical schools, medical training centers, public and private hospitals, national and regional societies, insurance institutions and others. The specific recommendations include:

1. Assess fatigue-related risks such as off-shift hours, consecutive shift work and staffing levels;

2. Examine processes when patients are handed off or transitioned from one caregiver to another, a time of risk that is compounded by fatigue;

3. Seek staff input on how to design work schedules that minimize the potential for fatigue and provide opportunities for staff to express concerns about fatigue;

4. Create and implement a fatigue management plan that include scientific strategies for fighting fatigue such as engaging in conversation, physical activity, strategic caffeine consumption and short naps;

5. Educate staff about good sleep habits and the effects of fatigue on safety of surgical patients;

6. Determine fatigue-related risks such as off-shift hours, consecutive shift work and staffing levels;

7. Examine processes when patients are handed off or transitioned from one caregiver to another, a time of risk that is compounded when fatigue exists;

8. Seek staff input on how to design work schedules that minimize the potential for fatigue and provide opportunities for staff to express concerns about fatigue;

9. Create and implement a fatigue management plan that includes scientific strategies for fighting it such as engaging in conversation, physical activity, strategic caffeine, consumption and short naps;

10. Educate staff about good sleep and the effects of fatigue on patient safety.

The Professional Wellbeing Committee of WFSA is planning future projects to evaluate what safeguards are presently in place across nations to ameliorate the problem of fatigue in anesthesia providers with the objective of developing firm recommendations in how National Anesthesia
Societies can implement policies for controlling fatigue. By having the Professional Wellbeing Committee of World Federation of Societies of Anesthesiologists and The Joint Commission working together towards common goal, hopefully the end result will be the worldwide improvement of patient safety and anesthesiologists' well being.

Can the planned approach prevent us from getting lured into working longer hours as a way to increase revenue and cover the ever-increasing clinical load? Perhaps not, but it should call attention to an existing problem and provide the clinician with international recommendations to support change within their own environment.

\section{Being aware of a problem is the first step in correcting a problem!}

Members of Professional Wellbeing Committee from World Federation of Societies of Anesthesiologists

Roger Moore, USA

Pratyush Gupta, India

Gastão F. Duval Neto, President

\section{References}

1. Howard SK, Rosekind MR, Katz JD, Berry AJ - Fatigue in anesthesia. Anesthesiology. 2002;97(5):1281-1294.

2. Howard SK, Gaba DM, Smith BE et al. - Simulation study of rested verses sleep-deprived anesthesiologists. Anesthesiology. 2003;98(6):1345-1355.

3. Wikipedia. Fatigue (medical). Disponível em: http://en.wikipedia. org/wiki/Fatigue_(medical). Acessado em 22/11/2012.

4. Howard SK, Rosekind MR, Katz JD et al. - Fatigue in anesthesia. Implications and strategies for patient and provider safety. Anesthesiology. 2002;97:1281-1294

5. Czeisler CA - The Gordon Wilson lecture: work hours, sleep, and patient safety in residency training. Trans Am Clin Climatol Assoc. 2006;117.

6. Czeisler, CA - Medical and genetic differences in the adverse impact of sleep loss on performance: ethical considerations for the medical profession. Trans Am Clin Climatol Assoc. 2006;117:159-188.

7. Park CS - Fatigue: not just a problem for residents. Newsletter. 2012;76(10):22-24.

8. Ward ME, Bullen KE, Charlton JE - Fatigue and anesthetists. Oxford, The Association of Anaesthetists of Great Britain and Ireland, 2004.

9. Statement of fatigue and the anaesthetist, published by Australian and New Zealand College of Anaesthetists, July 2004.

10. Arnedt JT, Owens J, Crouch M, Stahl J, Carskadon MA Neurobehavioral performance of residents after heavy night call vs after alcohol ingestion. JAMA. 20058;294(9):1025-1032.

11. West C - Association of resident fatigue and distress with perceived medical errors. JAMA.2009;302(12):1294-1300.

12. Kahn LT, Corrigan JM, Donaldson MS - To err is human: building a safer health system. Washington, DC, National Academy Press, 1999;1-223.

13. Joint Commission - Sentinel Event Alert - Health care worker fatigue and patient safety, 2011;48. 


\section{COMPLEMENTARY RECOMMENDED}

\section{BIBLIOGRAPHY}

1. Institute of Medicine - Sleep disorders and sleep deprivation: an unmet public health problem. March 21, 2006. Available at: http://www.iom.edu/Reports/2006/Sleep-Disorders-and-SleepDeprivation-An-Unmet-Public-Health-Problem.aspx.

2. Institute of Medicine - Resident duty hours: enhancing sleep, supervision, and safety. December 15, 2008. Available at: http:// www.iom.edu/Reports/2008/Resident-Duty-Hours-Enhancing-SleepSupervision-and-Safety.aspx.

3. Institute of Medicine - Keeping patients safe: transforming the work environment of nurses. Washington, DC: National Academy Press, November 3, 2003. Available at: http://iom. edu/Reports/2003/Keeping-Patients-Safe-Transforming-the-WorkEnvironment-of- Nurses.aspx.
4. Agency for Healthcare Research and Quality - Patient Safety and Quality: An Evidence-Based Handbook for Nurses. AHRQ Publication No. 08-0043, April 2008. Available at: http: / / www. ahrq.gov/qual/nurseshdbk/.

5. Lockley SW, Barger LK, Ayas NT et al. Effects of health care provider work hours and sleep deprivation on safety and performance. Jt Comm J Qual Patient Saf. 2007;33(11)7-18.

6. Blum AB, Shea S, Czeisler CA et al. - Implementing the 2009 Institute of Medicine recommendations on resident physician work hours, supervision, and safety. Nat Sci Sleep. 2011;3:139. 